\title{
Assessing a Ghanaian University's Real Estate Teaching and Learning
}

\author{
Emmanuel Kofi Gavu ${ }^{1,2}$
}

\author{
${ }^{1}$ Department of Land Economy, Kwame Nkrumah University of Science and Technology (KNUST), \\ Kumasi, Ghana. \\ ${ }^{2}$ Fakultät Raumplanung, Lehrstuhl Landschaftsökologie und Landschaftsplanung, Techniche Universität \\ Dortmund, Germany.
}

To cite this article: Gavu, E.K. (2018). Assessing a Ghanaian University's Real Estate Teaching and Learning. Journal of African Real Estate Research, 3(1), pp.21-38. DOI: 10.15641/jarer.v1i1.492.

\begin{abstract}
Just as curriculums and teaching styles vary, the experiences of students are varied and complex. This study aims to understand how students rate the undergraduate programmes at the Department of Land Economy (DoLE) within the Kwame Nkrumah University of Science and Technology (KNUST) Kumasi, Ghana. It studies the quality of education received alongside the expectations of students. To assess these variables, this study adopts and modifies the Student Engagement Questionnaire (SEQ) developed by Kember and Leung (2009). As part of this methodology, 312 students in their third and final year of DoLE's BSc in Land Economy and BSc in Real Estate participated in this assessment. Their responses were measured using a five-point Likert scale which consisted of 18 different scales. The scales were checked for reliability using Cronbach alpha values. Using this methodology, the study was able to conclude that more than $50 \%$ of respondents agreed that the quality of the programme met their expectations. Furthermore, students generally realised an improvement of their critical thinking and problem-solving capabilities. In contrast to this, students also emphasised a lack of feedback and an overwhelmed system of educational resources. It is worth noting that the SEQ, as a diagnostic tool, should be treated as being indicative, rather than absolute. Therefore, this study looks at the state of education from a Ghanaian student perspective. It highlights where there is room for improvement and ways in which future research can look at this issue from a broader industry standpoint. Education and learning must continuously evolve to meet the needs of students and be reflective of the times.
\end{abstract}

Keywords: Assessment; Teaching and Learning; Real Estate; Student Engagement Questionnaire; Ghana 


\section{Introduction}

Real estate education in Ghana is run by five public universities: Kwame Nkrumah University of Science and Technology (KNUST); University for Development Studies (UDS); Kumasi Technical University (KTU); Ghana Institute of Management and Public Administration (GIMPA); and University for Professional Studies, Accra (UPSA). KNUST is revered as the pioneering institution with regards to real estate education. The Department of Land Economy (DoLE), established in the 1966/67 academic year, was one of the first departments at KNUST with the mission to train world-class land economy and real estate professionals capable of finding solutions to the contemporary issues in Ghana's Real Estate sector.

From the outset, the department ran an undergraduate programme in Land Economy (4-year BSc) and a Land Management postgraduate (MSc and PhD) programme. The programmes aimed to incrementally address current issues as well as fundamental analysis of the real estate sector with each year of study. Both programmes focused attention on the role of policymakers in establishing regulatory frameworks within which land and its related markets operate. As well as the role of the private sector in owning, managing and developing physical and financial assets within those markets. This dual role analysis offers the department and its courses a better opportunity to address issues of concern in real estate and related sectors with time. While these programmes continue, there have been several changes in the education system at the university. Since the 2009/10 academic year, the DoLE has added another undergraduate programme in real estate to its academic offerings. Earlier in 2005, the university began to reorganise its departments, faculties and colleges. The goal was to make its departments more centred and interconnected. In doing so, the university introduced the collegiate system. This meant that similar programmes were grouped together in a college within the university. Trigwell (2005) mentions the collegiate system encompasses a set of interactions with students within their field of study but also from other disciplines. Thus, the collegiate system at KNUST began to foster multidisciplinary collaboration among faculty members and students, improved teaching, learning, and research opportunities. Over the years the DoLE has produced thousands of graduates serving many sectors of the economy, not limited to the real estate industry and its related sectors.

The current state of the university's programmes mirrors the times as well as the needs of the industry and government. In a globalised world, competition from other tertiary institutions in Ghana and abroad keep increasing. In the face of a rapid increase in numbers from students of diverse backgrounds, the department's approach to teaching and learning is pressured to meet worldclass standards. In this international climate, many studies have therefore explored the relationship between course assessment and programme improvement (de Weert, 1990; Gray, 2002; Booth, 2006; Combs et al., 2008; Newell et al., 2010; Newell, 2013; Poon, 2015). Typical course evaluations do not provide sufficient information about the quality of programmes. To receive the right kind of feedback helps to improve quality of education as per industry expectations. Without a better understanding of the problems of 
the department, it is difficult to know whether the quality of teaching and learning is meeting student needs as well as the needs of the job market.

It is not known how students, lecturers, and other supporting staff generally rate the level of teaching and learning in the DoLE at KNUST. In this time of change, it becomes essential to ask questions of self-regulation: How frequently are reviews and assessments done to facilitate or improve teaching and learning experiences? What are the strategic niche of departments and the relevance of teaching and research departments to the industry? The need for these kinds of periodic reviews will help put teaching and research departments at a level where continuous improvement in course content is readily achieved.

There is a perceived gap between the skills and competencies needed by students and what the DoLE offers regarding teaching standards. With this context in mind, this study aims to review teaching and learning activities of the DoLE so that the department can consistently promote quality education. Consequently, its overarching objective is to recommend new and innovative approaches that suit a real estate department and industry needs. There is a need for the quality of teaching and learning to be assessed, as it is vital to competitiveness in an increasingly globalised knowledge society (Van der Wende, 2003, Materu, 2007).

\subsection{The Need for an Improved Assessment}

The DoLE, like other departments at KNUST, is faced with pressing issues that hamper teaching and learning. Concerns from graduate employers seem to suggest that what students are taught does not match the requirements of the job market. An assessment is done every year to evaluate courses and lecturers. Over the years it has been observed that students' participation in regular KNUST university-wide course evaluations has dwindled. Furthermore, the results from such assessments are not diagnostic enough to bring out and improve quality issues.

There is the need for an assessment of teaching and learning at the department to evaluate its quality to meet market demands and review obsolete theoretical methods against current practices. This calls for a review of the department's curriculum to bring on board analytical courses to meet market concerns. More so, a good learning environment/infrastructure must be in place. Students come to class and are made to stand through lectures. Large class sizes do not encourage effective one-to-one interaction with students. Assignments are seldom given, and the mode of assessing students' knowledge of the course is reduced to mid-semester and end of term examinations. Quality assurance is crucial in addressing these challenges (Salmi, 2003). There are increasing calls for accountability, both on the part of students and staff alike, as a means to improve educational outcomes at the university (Materu, 2007). The need for improving teaching and learning has been previously underscored (Adams, 1993, Hanushek and Woessmann, 2007). This research, therefore, seeks to examine ways to measure the quality 
of education at a programme level to improve and suggest new and innovative ways of tackling the issues.

\subsection{Research Objectives}

This study aims to review the teaching and learning activities of the DoLE at KNUST and thus its ability to promote quality education. To operationalise the aim, objectives and research questions have been formulated of which specific answers need to be obtained. Table 1 shows the research objectives with the specific research questions to address them.

Table 1: Research Objectives and Questions

\begin{tabular}{|l|l|l|}
\hline No. & Research objectives & Research questions \\
\hline i & $\begin{array}{l}\text { To examine the current state of } \\
\text { teaching and learning at the } \\
\text { department. }\end{array}$ & $\begin{array}{l}\text { What is the current state of teaching and learning in the } \\
\text { department? }\end{array}$ \\
\hline ii & $\begin{array}{l}\text { To examine the major problems } \\
\text { that inhibit quality teaching and } \\
\text { learning experience at the } \\
\text { department. }\end{array}$ & $\begin{array}{l}\text { What are quality teaching and learning? } \\
\text { teaching and learning experience? }\end{array}$ \\
\hline iii & $\begin{array}{l}\text { To examine best practices of } \\
\text { teaching and learning and how } \\
\text { they can be adapted to suit } \\
\text { department's needs }\end{array}$ & $\begin{array}{l}\text { What best practices exist elsewhere in terms of teaching } \\
\text { and learning? } \\
\text { persist? }\end{array}$ \\
\hline iv & $\begin{array}{l}\text { To develop an assessment criteria } \\
\text { to measure teaching and learning } \\
\text { at the department. }\end{array}$ & Which assessment criteria already exist? \\
\hline
\end{tabular}

\subsection{Teaching and Learning Assessments}

Ensuring quality of teaching and learning in universities is a significant concern (Biggs, 2001; Biggs \& Tang, 2003; 2007; Biggs, 2011). The current standard practice of international tertiary institutions is that there needs to be quality assessments of what is taught in the classroom. This is very important as it serves as a means to improve the performance of students based on feedback from course evaluations and assessments. Kember and Leung (2009) highlight that evaluation at the level of instructor or course is almost universal. The university, as an institution, has specified various procedures for awarding degrees and outlined what students ought to do to pass examinations and graduate. It is therefore, a self-regulating body with the ability to set in motion processes for transformation. The entity itself needs assessment as well as the various parts it consists of.

Fraser (1998) mentions that: "A 'learning environment' refers to the social, psychological and pedagogical contexts in which learning occurs and which affect student achievement and attitudes" (Fraser, 1998: p.3). This is a very 
broad definition which is more student-focused at the same time teachercentred. One common form of evaluating this kind of learning environment is to focus on the experience of students throughout their course of study to gain a better understanding of their perception of quality to improve course delivery. Numerous surveys have been developed to assess how students view a range of campus experiences which help them in their social and academic integration. Common surveys used in universities include the College Student Experience Questionnaire (Pace \& Kuh, 2007) and the Course Experience Questionnaire (CEQ; Ramsden, 1991; Newell et al., 2010). Ramsden's (1991) questionnaire was aimed at assessing teaching effectiveness at the level of the whole degree programme. The CEQ has many versions, with scales for Good Teaching, Generic Skill, Clear Goal and Standard, Appropriate Workload, and Appropriate Assessment. One of the limitations of the CEQ is that the construct is restricted to a five-point Likert scale; thus, feedback is restricted to five variables. Teaching is seen to be multidimensional, and therefore a well-designed teaching evaluation instrument should have multiple scales (Marsh, 1987). Moreover, social and psychological aspects as mentioned in Fraser's (1998) definition are missing in the CEQ. The DoLE currently uses an assessment construct that leans towards the CEQ but not in its entirety.

\section{Methodology}

To ensure the broadest possible data and opinion coverage, the study employed both qualitative and quantitative research designs (i.e. a mixedmethod approach). This methodology was selected to fulfil the different objectives discussed earlier. It included both formal and informal discussions and the administration of questionnaires to students. Also, a literature survey was used to gather information on the current trends to obtain meaningful insights to this phenomenon.

Sourcing of data was done using both primary and secondary sources. Primary sources included the use of structured questionnaires and interviews. The sampling procedure used was purposive sampling of students. Secondary sources of data included journals, reports, and internet publications. These aided in reviewing the literature on the existing situation to better appreciate the topic.

The first part of this research design was to develop and formulate an appropriate assessment criterion which meets the department's current needs. Thereafter, students were selected to partake in the assessment. The final step of the design was to analyse the results derived from these assessments. This design was challenging especially in the development of the assessment criteria as many similar assessments already exist in the literature to the extent that selection and justification were challenging.

\section{Development of an Improved Questionnaire}

KNUST periodically performs an assessment of lecturers and the course (teaching evaluation). Students partake in this assignment and necessary feedback goes to select lecturers. Over the years it has been understood that 
most of the students do not take these assessments seriously due to assessment fatigue (Adams \& Umbach, 2012). Furthermore, they do not see how their inputs are incorporated into a better course design and therefore feel discouraged. Also, the participation of third and final year students was noted to be diminished because of the students' perceived non-incorporation of their contributions.

Considering this background, through an examination of literature and guided by principles as mentioned by Kember and Leung (2009), the author opined that the design of new assessment criteria should incorporate the following:

1. The assessment needs to be diagnostic enough to identify strengths and weaknesses so that the feedback would lead to an action plan for improvement.

2. The assessment needs to be consistent with research into teaching and learning environments.

These two guiding principles mean that there should be a range of scales to satisfy various aspects of teaching, learning and environment. At the same time, it has also been understood that students are reluctant to answer a questionnaire which they consider too lengthy.

Considering these conclusions, the author has adopted the Student Engagement Questionnaire (SEQ) for the following reasons:

1. The questionnaire is outcome based;

2. It can be used across disciplines

3. It is more holistic (to embrace Fraser's (1998) definition).

A set of initial tests were run to ascertain the usefulness of this questionnaire. Helpful feedback was gained for future improvement (see Kember \& Leung, 2005). There are two main parts of the questionnaire;

1. A section seeking feedback on students' perceptions of their academic development during their degree programme based on a set of generic capabilities.

2. A section seeking feedback on perceptions of the quality of elements of the teaching and learning environment.

The questionnaire had nine scales to measure the teaching environment. Three higher orders are captured under this item. The first one, Teaching, is measured by the criteria of active learning, teaching for understanding, assessment, and coherence of curriculum. The second, Teacher-Student Relationship, measures the relationship between lecturers and students, and feedback to assist learning. Lastly, under Student-Student Relationship, there are the two items including the relationship with other students and cooperative learning. This concept of measuring and assessing the learning environment closely resembles the definition given by Fraser (1998). 
The list of all 18 scales used in this research work (adapted from Kember \& Leung, 2009) are provided in the appendix. In line with the methodology, the study did not include the two open-ended questions as in the original questionnaire. This decision was made so that unclear student responses would be minimised so that evaluation would be more consistent. Furthermore, preference was given to closed-ended questionnaires rather than open-ended questionnaires so as not to obtain varied answers. The two questions that were omitted from Kember and Leung's questionnaire were:

1. What are the best aspects of your programme?

2. Which aspects are most in need of improvement?

In place of these, the study added one more item for overall satisfaction of the course. This was found to be missing in the original questionnaire. This item was added to allow students to rate the overall course quality. The reason close-ended questions were used instead of open-ended questions is because of the disadvantages of using open-ended questionnaires in surveys. These disadvantages include the fact that open-ended questionnaires require extensive coding, there is a larger non-response rate, and they produce more missing data (Geer, 1998; Reja et al., 2003).

The questionnaire used a five-point Likert scale with the responses ranging from Strongly Disagree (1) to Strongly Agree (5).

1 - Strongly Disagree

2 - Disagree

3 - Only to be Used if a Definite Answer is not Possible

4 - Agree

5 - Strongly Agree

In all, the modified criteria used in the study consist of 18 distinct criteria to measure the quality of teaching and learning (see appendix).

Table 2 shows the number of students from the various classes whose responses were included in the final analysis of this research work. Third and fourth (final) year students studying BSc Land Economy and BSc Real Estate programmes were the only classes used for the research. They were understood to be those who could give more conclusive feedback about the performance of teaching and learning when compared to their colleagues in first and second years who have had limited exposure to the programme.

The questionnaires were administered at the end of the second semester of the 2012/2013 academic year when students had completed all their semester examinations. This was to avoid any premature answers and guesswork. The overall response rate was $93 \%$. Per class, the response rate was $82 \%, 96 \%$, $99 \%$ and a 100\% for Land Economy Year 3 (LE3), LE4, RE3, and Real Estate Year 4 respectively. 
Table 2: Number of Respondents from Each Class

\begin{tabular}{|l|l|}
\hline Description & Number of respondents \\
\hline BSc Land Economy Year 3 & 81 \\
\hline BSc Land Economy Year 4 & 118 \\
\hline BSc Real Estate Year 3 & 69 \\
\hline BSc Real Estate Year 4 & 44 \\
\hline Total & $\mathbf{3 1 2}$ \\
\hline
\end{tabular}

\section{Results}

Quantitative data was collected and analysed to present the issues discussed under broad themes.

\subsection{Reliability of the Questionnaire}

Validity and reliability are two fundamental elements in the evaluation of a measurement instrument (Kember \& Leung, 2009). The reliability of the scales was checked using Cronbach alpha values (Table 3). The Cronbach alpha is a coefficient of internal consistency. It is the most widely used objective measure of reliability expressed as a number ranging from 0 to 1 (Tavakol \& Dennick, 2011)

Table 3: Cronbach Alpha Coefficient for Scales in the Questionnaire

\begin{tabular}{|l|l|l|}
\hline Scale & No. of items & Alpha \\
\hline Capability & & \\
Critical thinking & 2 & 0.71 \\
Creative thinking & 2 & 0.72 \\
Self-managed learning & 2 & 0.48 \\
Adaptability & 2 & 0.56 \\
Problem-solving & 2 & 0.71 \\
Communication skills & 2 & 0.72 \\
Interpersonal skills and group work & 2 & 0.61 \\
Computer literacy & 2 & 0.80 \\
Teaching and Learning Environment & 2 & \\
Active learning & 2 & 0.49 \\
Teaching for understanding & 0.46 \\
Feedback to assist learning & 2 & 0.39 \\
Assessment & 3 & 0.63 \\
Relationship between teachers and students & 2 & 0.63 \\
Workload & 2 & 0.66 \\
Relationship with other students & 2 & 0.70 \\
Cooperative learning & 2 & 0.73 \\
Coherence of curriculum & 2 & 0.74 \\
\hline
\end{tabular}

The formula is given as:

$$
\alpha=\mathrm{K} /(\mathrm{K}-1)\left[1-\left(\sum \sigma^{2} / \sigma_{\text {total }^{2}}\right]\right.
$$


Where $K$ is the number of items, $\left(\sum \sigma^{2}\right.$ is the sum of the $\mathrm{K}$ item score variances, and $\sigma_{\text {total }}{ }^{2}$ is the variance of scores on the total measurement. The formula is interpreted as:

$$
\begin{aligned}
& \text { (Number of items/ Number of items }-1) *[1-(\text { sum of variancel } \\
& \text { standard deviation } \wedge 2)]
\end{aligned}
$$

Reliability estimates show the amount of measurement error in a test (See Tavakol \& Dennick, 2011 for further explanation). Higher values of alpha are preferable. However, the general rule suggests that an alpha of $\geq 0.70$ is more desirable. If items are correlated to each other, alpha values will increase and vice versa (Tavakol \& Dennick, 2011). From Table 3, one can conclude that eight of the measured criteria fall within acceptable alpha values of above 0.70 . However, items that do not fall within this range should not be dismissed in the interpretation given the reasons above as they may add qualitative value to the study.

\subsection{Diagnostic Power}

For an instrument to improve the quality of teaching and learning, it must be designed in such a way that it can identify strengths and weaknesses (Kember $\&$ Leung, 2009). The next phase of the analysis focused on some of the results to identify how diagnostic feedback from the evaluation could help improve teaching and learning at the DoLE at KNUST. The next section details some of the results and how they are indicative of the department's performance. Four out of 18 criteria are discussed subsequently. This is to limit the discussion to critical elements that are of concern to students, faculty and employers. Thematic areas for further discussion are Critical Thinking, Feedback from staff, Problem-solving capabilities and career prospects, and Overall quality of the Bachelor's programme.

\section{(i) Critical Thinking}

Figure 1 shows a descriptive analysis of the Critical Thinking criteria. Students in various classes were asked to rate two criteria relating to their development in critical thinking using a Likert scale (See questions 1 and 2 of Appendix). They rated themselves high. From the graph, many of students believe they have developed themselves in critical thinking abilities.

Students agreed that this area of their academic life had improved. Only a few students (less than 5\%) do not agree with that assertion. This criterion is very crucial as students were asked to rate themselves to determine whether they were up to the task of critically examining dissenting and opposing views. 


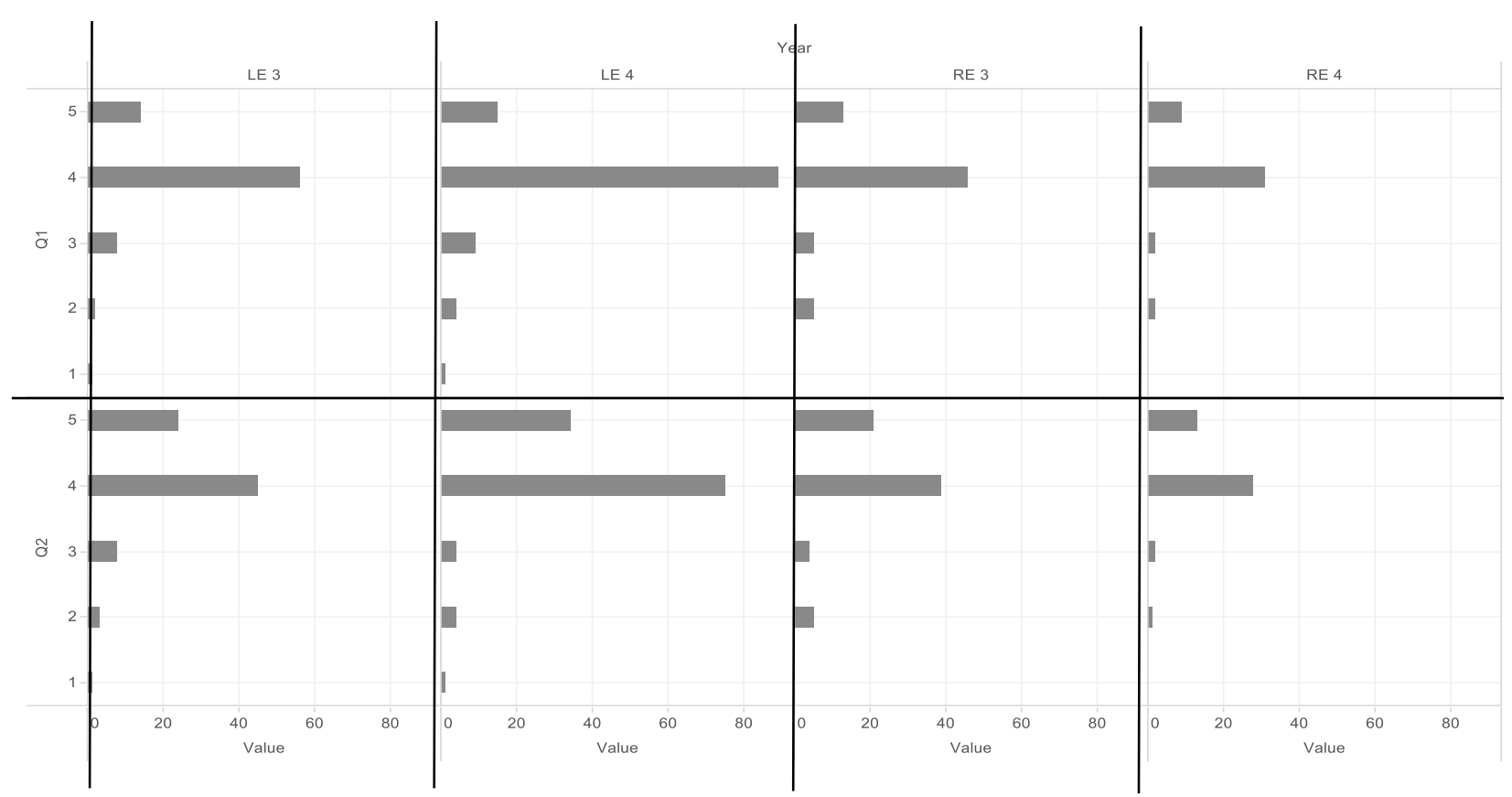

Figure 1: Score for Critical Thinking Criteria

(ii) Feedback from Staff

One of the criteria which did not have a strong internal coherency was the criterion that measured feedback students receive from staff. It had a Cronbach alpha value of 0.39 , the lowest of all the criteria measured. This result was to be expected as some of the students perceived that they do not receive useful feedback from teaching staff to enable them to know what is expected of them. Students were asked to rank questions 21 and 22 using the Likert scale 1 to 5.

Q21. When I have difficulty with learning materials, I find the explanations provided by the teaching staff useful.

Q22. There is sufficient feedback on activities and assignments to ensure that we learn from the work we do.

From Figure 2, it becomes apparent that a majority of the students (more than $45 \%$ in each class) do not agree to the assertion that they receive sufficient feedback on activities and assignments (question 22). The reason may be attributed to students' numbers increasing over the years. As a result, class assignments and short tests, which used to be administered, have either been stopped or continued but without adequate assessment or feedback to the students. It should also be noted that the university has subscribed to various e-journals that, should be accessed online. However, there has been difficulty in students getting access to learning materials both hard copies and e-copies. 


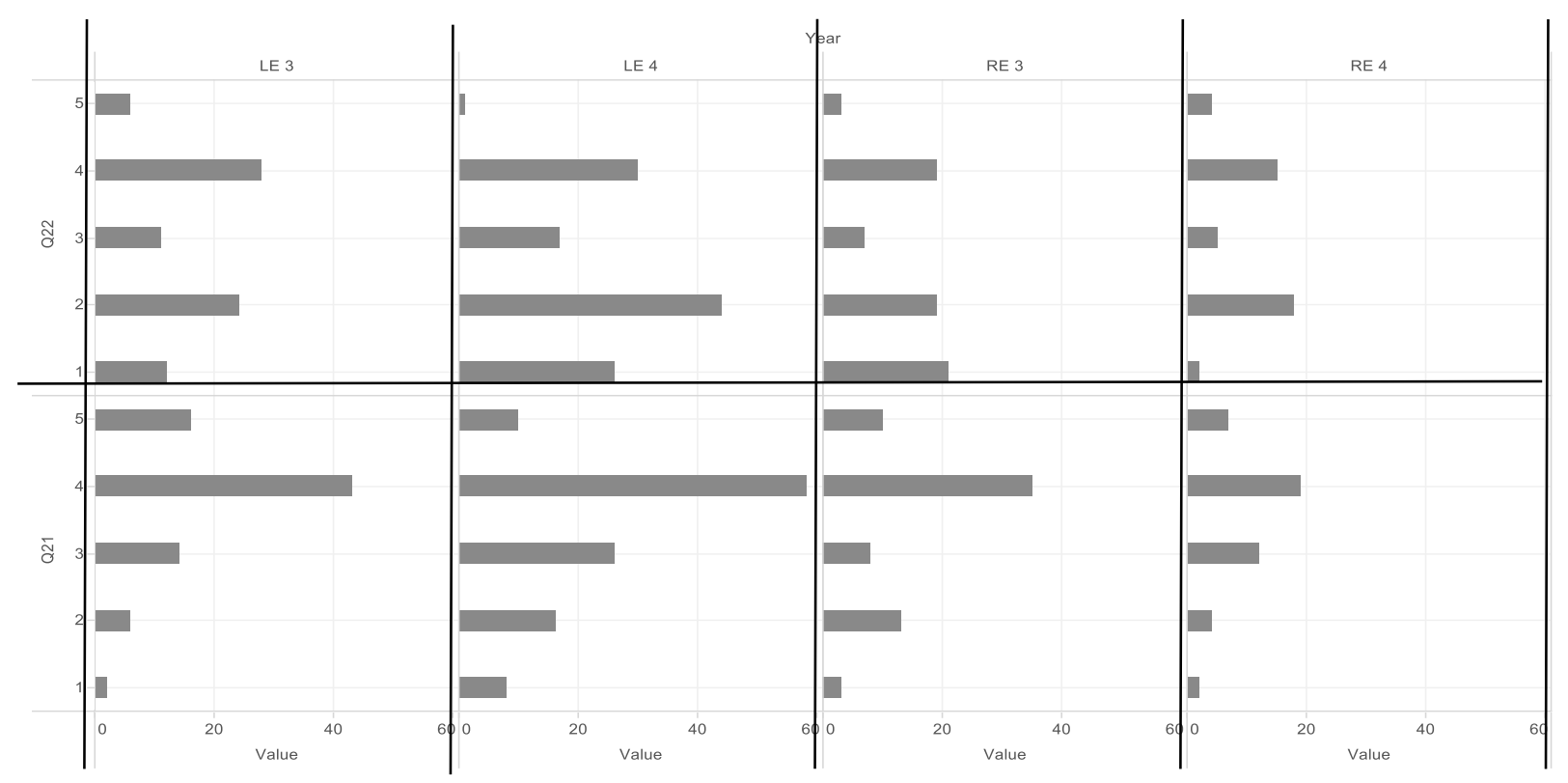

Figure 2: Feedback from Staff (questions 22 and 21)

A different trend emerges when the same students were asked if they had difficulty in getting learning materials (question 21). Majority of the students were of the view that explanations provided by teaching staff were useful. This response is at variance with the previous question

Table 4 shows the same results as in Figure 2 but in percentages to better appreciate the issues. The percentage of each score over the total score for each question was computed for the four different classes. In response to question 22, as many as $35 \%$ of students in LE3 agreed that there is sufficient feedback on activities and assignments. However, $37 \%$ and $41 \%$ in LE4 and RE4 respectively disagreed with that assertion. The interesting thing noted is that $30 \%$ of students in RE3 strongly disagreed with the same statement. The highest percentages in the table are highlighted for quick identification.

Table 4: Percentage Scores of Criteria Feedback from Staff

\begin{tabular}{|l|l|l|l|l|}
\hline Score & \multicolumn{4}{|c|}{ Year } \\
\hline Q.22 & LE3 & LE4 & RE3 & RE4 \\
\hline $\mathbf{5}$ & 7 & 1 & 4 & 9 \\
\hline $\mathbf{4}$ & 35 & 25 & 28 & 34 \\
\hline $\mathbf{3}$ & 14 & 14 & 10 & 11 \\
\hline $\mathbf{2}$ & 30 & 37 & 28 & 41 \\
\hline $\mathbf{1}$ & 15 & 22 & 30 & 5 \\
\hline
\end{tabular}

\begin{tabular}{|l|l|l|l|l|}
\hline Q.21 & LE3 & LE4 & RE3 & RE4 \\
\hline $\mathbf{5}$ & 20 & 8 & 14 & 16 \\
\hline $\mathbf{4}$ & 53 & 49 & 51 & 43 \\
\hline $\mathbf{3}$ & 17 & 22 & 12 & 27 \\
\hline
\end{tabular}




\begin{tabular}{|l|l|l|l|l|}
$\mathbf{2}$ & 7 & 14 & 19 & 9 \\
\hline $\mathbf{1}$ & 2 & 7 & 4 & 5 \\
\hline
\end{tabular}

A different trend emerges as shown in Table 4; the students generally agreed that when they have difficulty with learning materials, and explanations from teaching staff are useful. On the one hand, teaching staff are helpful, and on the other, they do not give sufficient feedback, according to the students rating. The results indicate a contradiction. This contradiction may stem from the fact that teaching staff deliver lectures to the best of their abilities during contact hours in class. At the same time, due to increasing student numbers, few assignments are given to ensure that teaching staff can mark and grade students accordingly.

\section{(iii) Problem-Solving Capabilities and Career Preparation}

One of the key criteria for assessing the quality of a teaching and learning environment is students' problem-solving capabilities. To answer this, students were asked to rate two statements (questions 9 and 10 of the questionnaire) namely:

Q9. I have improved my ability to use knowledge to solve problems in my field of study.

Q10. I am able to bring information and different ideas together to solve problems.

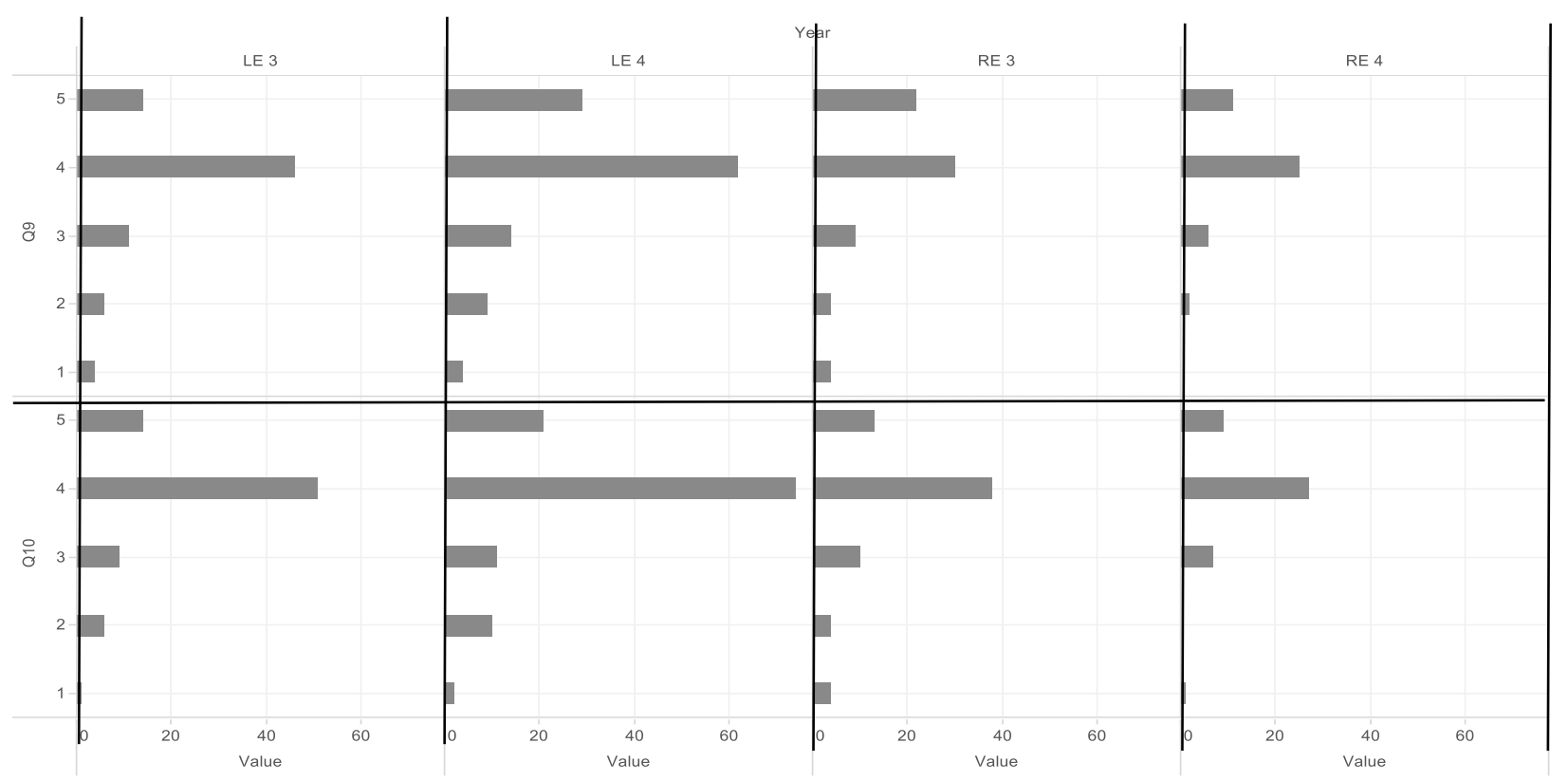

Figure 3: Problem-Solving Abilities (questions 9 and 10)

The results suggest that in terms of problem-solving abilities, the majority of the students (more than 70\% in each class) agreed with the statement that they had improved on this aspect and could solve problems on their own (Figure 3 ). University education, especially at the bachelor's level prepares students generally to work in any field and to think on their feet (Brooks, 2011). These 
responses attest to the fact that students know this aspect as very critical and thus learn to improve upon themselves.

\section{(iv) Overall Quality}

The last criterion considered in this research was to measure the overall quality of the programme (see Figure 4). This response was significant as it gives the students' impression of the quality they expect and see from the department. Students are key stakeholders in education. Anecdotal evidence suggests some academics are of the view that students cannot rank the quality of an educational programme because they do not know what they should learn until they are taught. The reason could be that students may be thought to be ill-informed concerning teaching expectations and thus need to be guided on what to do every step of the way. This view is short-sighted in today's context given that university education is shifting from teacherfocused to student-centred learning (Ramsden, 1991; Biggs, 2001; Gray, 2002; Biggs, 2011). Moreover, information received from student ratings can be used by individual instructors to improve the course in future years and to identify areas of strength and weakness by making comparisons with other departments (Van der Wende, 2003; Kember \& Leung, 2009). Such data accumulated over the years can enable detection of patterns of teaching development in the department. From the overall ranking of the quality of the programme, it was realised that more than $50 \%$ of students from all the classes sampled agreed that the quality of the programme is good.

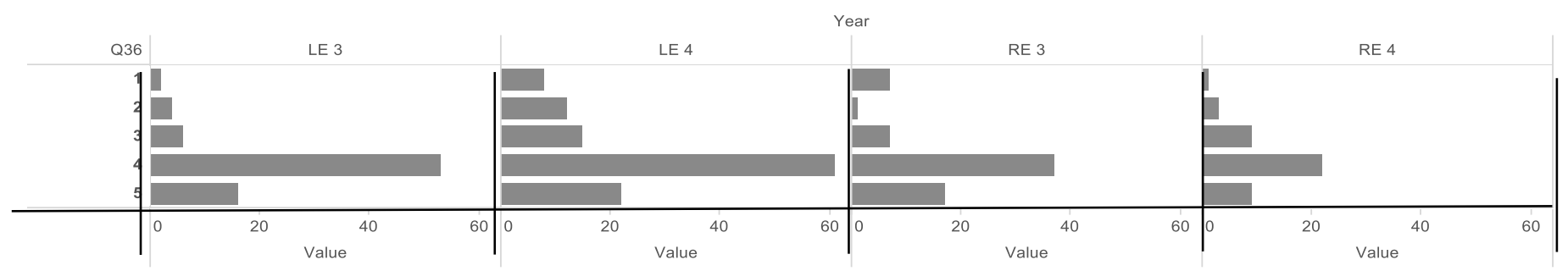

Figure 4: Overall Quality Of Programme (both Bsc Land Economy and Real Estate Students)

\section{Conclusion}

There are several questionnaires for assessing teaching courses, but one that assesses both teachings and learning is relatively scarce (Kember \& Leung, 2009). A significant influence on the achievement of learning outcomes is the teaching and learning environment, which is incorporated in the Student Engagement Questionnaire (SEQ) (Kember \& Leung, 2009).

The methodology and use of the SEQ provided criteria to measure the learning environment at the Department of Land Economy of KNUST. The questionnaire had nine scales to measure the teaching environment. Three higher orders are captured under this item: Teaching; Teacher-Student Relationship and Student-Student Relationship. This concept of measuring and assessing the learning environment closely resembles the definition given by Fraser (1998). 
The reliabilities of the scales used in this research work were established using the Cronbach alpha $(\alpha)$ coefficient. The construction of the various scales of measurement was adapted from Kember and Leung (2009) to suit the needs of the study. In deciding on the validity of the questionnaires, consultation was sourced from other lecturers in the department with the requisite expertise. Based on Cronbach alpha scores, areas which need further attention (based on Table 3) at the department include: (1) Self-managed learning; (2) Requisite feedback from staff to assist studies; (3) Teaching for understanding so students understand course design, course material and course content; and (4) Active learning that encourages student participation.

In conclusion, one of the advantages of this questionnaire instrument is its ability to identify the strengths and weaknesses based on students' responses. This is a diagnostic tool that should be treated as being indicative, rather than absolute. In that sense, responses gathered can be used to improve teaching and learning at the programme level. If this questionnaire instrument is adopted at other tertiary education institutions, college data averages could be compared with the department's (within the same college) to assess how the department performs in relation to others. Results could then be compared among departments to know critical areas to consider improving.

This research work is beneficial for various reasons. It offers stakeholders (which includes KNUST, DoLE, industry players, real estate practitioners in Ghana and students) an in-depth insight into the teaching and learning at the DoLE. Furthermore, it provides information to stakeholders about challenges of the department, which may assist them with identifying and prioritising needs for quality improvement purposes. Finally, it can be a basis for further comprehensive assessment of the performance of the department in terms of teaching and learning.

Students generally ranked themselves high concerning 'critical thinking' and 'general improvement in problem-solving capabilities'. However, findings also suggest that students lack adequate feedback from staff, which is partly attributable to increasing student numbers over the years (while academic staff numbers have remained constant). Moving forward, the department needs to ensure that there is an effective use of technology, less focus only on examinations, but also more report writing and presentation opportunities to improve students' self-confidence. Additionally, there is the need to liaise, coordinate and share ideas with other real estate departments (at other universities) to improve the quality of learning experience for students. This will go a long way to increase the quality of the teaching and learning. Moreover, it will also ensure that the standard that the department is striving to achieve meets internationally acceptable benchmarks.

This paper, therefore, proposes that future research should focus on rating the perceptions of industry players, real estate practitioners and teaching staff of the DoLE, on course content and quality. The perceptions can then be measured against the outcomes of this research, which could help the ensuing 
debate to strengthen the curriculum of DoLE and meet world standards in real estate education.

\section{Acknowledgements}

This research is kindly sponsored by IRE|BS Foundation for African Real Estate Research. I am very grateful to Surveyor Jonathan Zinzi Ayitey for his immense support and valuable suggestions. Also a warm appreciation to third and final year students of the 2012/ 2013 academic year group of the Department of Land Economy, KNUST for their contribution in answering the questionnaire. Last but not the least; special appreciation goes to my wife, Gertrude, and the rest of the family for support and encouragement when needed most.

\section{References}

Adams, D. (1993). Defining educational quality. Educational Planning, 9, pp. 3-18.

Adams, M. J., and Umbach, P. D. (2012). Nonresponse and online student evaluations of teaching: Understanding the influence of salience, fatigue, and academic environments. Research in Higher Education, 53(5), pp.576-591.

Biggs, J. (2001). The reflective institution: Assuring and enhancing the quality of teaching and learning. Higher Education, 41(3), pp.221238.

Biggs, J. and Tang, C. (2003). Teaching for Quality Learning at University, Society for Research into Higher Education and Open University Press, Berkshire: The Society for Research into Higher Education and Open University Press

Biggs, J., and Tang, C. (2007). Teaching for quality learning at university. Society for research into higher education, Berkshire: The Society for Research into Higher Education and Open University Press.

Biggs, J. B. (2011). Teaching for quality learning at university: What the student does. McGraw-Hill Education, $4^{\text {th }}$ Edition, McGraw-Hill.

Booth, L. (2006). A database to promote continuous program improvement, In Proceedings of the 7th conference on Information technology education, October 2006, pp.83-88, ACM.

Brooks, D. C. (2011). Space matters: The impact of formal learning environments on student learning. British Journal of Education Technology, 42(5), pp.719-726.

Combs, K. L., Gibson, S. K., Hays, J. M., Saly, J., and Wendt, J. T. (2008).

Enhancing curriculum and delivery: Linking assessment to learning objectives. Assessment and Evaluation in Higher Education, 33(1), pp.87-102.

Fraser, B. J. (1998). The birth of a new journal: Editor's introduction Learning Environments Research, 1, pp.1-5.

Geer, J. G. (1988). What do open-ended questions measure? Public Opinion Quarterly, 52(3), pp.365-367.

Gray, P. J. (2002). The Roots of Assessment. Building a scholarship of assessment, Wiley, p.49.

Hanushek, E. and Woessmann, L. (2007). The role of education quality for 
economic growth. World Bank Policy Research Working Paper No. 4122.

Kember, D. and Leung, D.Y.P. (2005). The influence of active learning experiences on the development of graduate capabilities. Studies in Higher Education, 30, pp.157-172.

Kember, D. and Leung, D.Y.P. (2009). Development of a questionnaire for assessing students' perceptions of the teaching and learning environment and its use in quality assurance. Learning Environments Research, 12, pp.15-29.

Marsh, H. W. (1987). Students' evaluations of university teaching: Research findings, methodological issues, and directions for future research, International Journal of Educational Research, 11, pp.255-388.

Materu, P.N. (2007). Higher education quality assurance in Sub-Saharan Africa: status, challenges, opportunities and promising practices. World Bank Publications.

Newell, G. (2013). Assessing property student satisfaction with their property education experience in an Australian University. Pacific Rim Property Research Journal, 19, pp.133-149.

Newell, G., Susilawati, C. and Yam, S. (2010). Student perceptions of the quality of property education in Australia: 1994 - 2009. Pacific Rim Property Research Journal, 16(4), pp.400-422.

Pace, C. R., and Kuh, G. D. (2007). The college student experiences questionnaire assessment program. Retrieved August 22, 2013, from http://cseq.iub.edu/cseq_generalinfo.cfm.

Poon, J. (2015). A study of real estate student satisfaction in Australia. Pacific Rim Property Research Journal, 21(3), pp.215-233.

Ramsden, P. (1991). A performance indicator of teaching quality in higher education: The Course Experience Questionnaire. Studies in Higher Education, 16, pp.129-150.

Reja, U., Manfreda, K. L., Hlebec, V., and Vehovar, V. (2003). Open-ended vs. close-ended questions in web questionnaires. Developments in Applied Statistics, 19, pp.159-177.

Salmi, J. (2003). Constructing knowledge societies: new challenges for tertiary education. Higher Education in Europe,28, pp.65-69.

Tavakol, M. and Dennick, R. (2011). Making sense of Cronbach's alpha. International Journal of Medical Education, 2, pp.53-55.

Trigwell, K. (2005). Teaching-research relations, cross-disciplinary collegiality and student learning. Higher Education, 49(3), pp.235254.

Van der Wende, M.C. (2003). Globalisation and access to higher education Journal of Studies in International Education, 7, pp.193-206. 


\section{Appendix}

\section{The Student Engagement Questionnaire}

\section{Instructions}

In answering this questionnaire, please think about the course as a whole rather than identifying individual subjects, topics or lecturers. The questions relate to general issues about your course, based on comments that students have often made about their experiences of university teaching and studying. Your responses are strictly confidential.

Please indicate your level of agreement with the statements below. Please choose the one most appropriate response to each question.

1 - Strongly Disagree

2 - Disagree

3 - Only to be Used if a Definite Answer is not Possible

4 - Agree

5 - Strongly Agree

\section{Critical thinking}

1.1. I have developed my ability to make judgments about alternative perspectives.

1.2. I have become more willing to consider different points of view.

\section{Creative thinking}

2.1. I have been encouraged to use my own initiative.

2.2. I have been challenged to come up with new ideas.

\section{Self-managed learning}

3.1. I feel that I can take responsibility for my own learning.

3.2. I have become more confident in my ability to pursue further learning.

\section{Adaptability}

4.1. During my time at university, I have learnt how to be more adaptable.

4.2. I have become more willing to change my views and accept new ideas.

\section{Problem-solving}

5.1. I have improved my ability to use knowledge to solve problems in my field of study.

5.2. I am able to bring information and different ideas together to solve problems.

\section{Communication skills}

6.1. I have developed my ability to communicate effectively with others.

6.2. In my time at university, I have improved my ability to convey ideas.

\section{Interpersonal skills and group work}

7.1 I have learnt to become an effective team or group member.

7.2 I feel confident in dealing with a wide range of people.

\section{Computer literacy}

8.1. I feel confident in using computer applications when necessary.

8.2. I have learnt more about using computers for presenting information. 


\section{Active learning}

9.1. Our teaching staff use a variety of teaching methods.

9.2. Students are given a chance to participate in classes.

\section{Teaching for understanding}

10.1. The teaching staff try hard to help us understand the course material.

10.2. The course design helps students understand the course content.

\section{Feedback to assist learning}

11.1. When I have difficulty with learning materials, I find the explanations provided by the teaching staff useful.

11.2. There is sufficient feedback on activities and assignments to ensure that we learn from the work we do.

\section{Assessment}

12.1. The program uses a variety of assessment methods.

12.2. To do well in assessment in this program you need to have good analytical skills.

12.3. The assessment tested our understanding of key concepts in this program.

\section{Relationship between teachers and students}

13.1. The communication between teaching staff and students is good.

13.2. I find teaching staff helpful when asked questions.

\section{Workload}

14.1. I manage to complete the requirements of the program without feeling unduly stressed.

1.2. The amount of work we are expected to do is quite reasonable.

\section{Relationship with other students}

15.1. I feel a strong sense of belonging to my class group.

15.2. I frequently work together with others in my classes.

\section{Cooperative learning}

16.1. I have frequently discussed ideas from courses with other students out-of-class.

16.2. I have found that discussing course material with other students outside classes has helped me to reach a better understanding of the material.

\section{Coherence of curriculum}

17.1. I can see how courses fitted together to make a coherent program of study for my major. 17.2. The program of study for my major was well integrated.

18. Course quality

18.1. Overall, I am satisfied with the quality of the course.

Thank you 